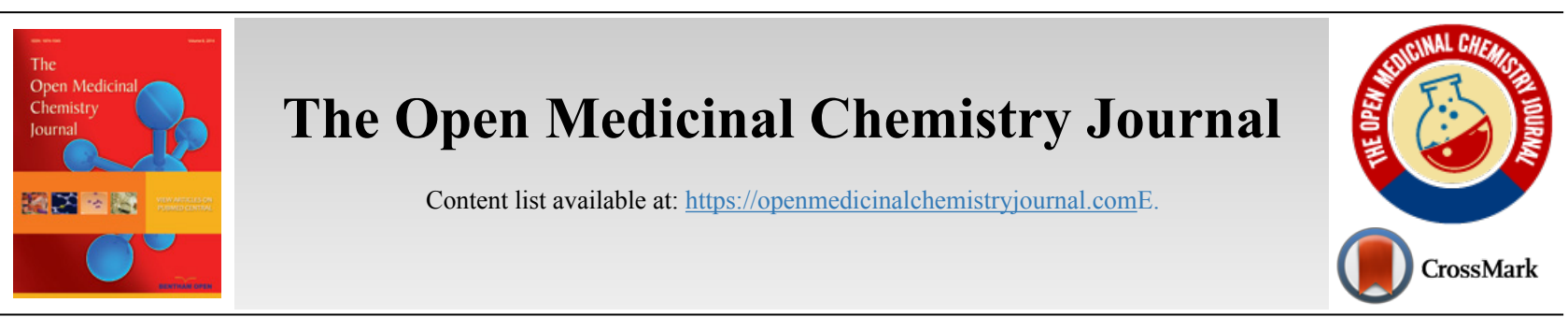

\title{
EDITORIAL
}

\section{Post-Coronavirus World and Prevalence of Type 2 Diabetes}

\author{
Alireza Tavilani ${ }^{1}$ and Ebrahim Abbasi ${ }^{2, *}$ \\ ${ }^{1}$ Islamic Azad University, Hamadan Branch, Hamedan, Iran \\ ${ }^{2}$ Department of Clinical Biochemistry, School of Medicine, Hamadan University of Medical Sciences, Hamadan, Iran
}

Article History

Received: May 31, 2021

Revised: October 11, 2021

Accepted: November 30, 2021

Once the pandemic of Coronavirus disease 2019 (COVID-19) settles down, monitoring programs are needed for overweight and sedentary patients. The sedentary habits induced by the COVID-19 (quarantine and bed rest(can increase the risk of cardiovascular disease, metabolic syndrome, insulin resistance (IR), and neuromuscular disorders. IR in a long time can raise the risk for various disorders, such as type 2 diabetes, hypertension, cardiovascular disease, and cancer $[1,2]$. A few days of bed rest (e.g., due to COVID-19) are adequate to induce IR, muscle atrophy, fat deposition, oxidative stress, and low-grade inflammation [3].

COVID-19 leads to an imbalance in angiotensin-converting enzyme 2 (ACE2), which can aggravate glucose metabolism. Disturbance of the ACE2 pathway is directly associated with IR. In the pancreas, binding of the coronavirus to ACE2 causes injury to islet cells and induces IR [4]. A 3-year follow-up of severe acute respiratory syndrome coronavirus (SARS-CoV) patients reported that more than $50 \%$ of the cases have diabetes during hospitalization. Interestingly, these subjects had no history of steroid therapy and diabetes. Nevertheless, after 3 years of recovery from the SARS-CoV disease, about $5 \%$ of cases remained diabetic [4]. In a similar manner, COVID-19 patients will have a chance of diabetes in the future.

COVID-19 infection in some people can have life-changing effects. COVID-19 infection may lead to months, years, or even a lifetime of debilitating symptoms that significantly decrease patients' quality of life.

COVID-19 infection may increase the risk of IR and metabolic syndrome $[3,5]$. Some of the COVID-19 patients experienced sedentary life or were hospitalized for at least 7 days. Moreover, some COVID-19 patients experienced pneumonia. An association between the disease and IR has been documented even after several years of lung disease, such as pneumonia [6]. Numerous factors can lead to hyperglycemia and IR in COVID-19 patients, including the use of medications

\footnotetext{
* Address correspondence to this author at the Department of Clinical Biochemistry, Faculty of Medicine, Hamadan University of Medical Sciences, Hamadan-Iran; E-mail: 7abbasi@gmail.com
}

during hospitalization (lithium, exogenous cortisol, $\beta$-blockers, and vasopressors), oxidative stress, inflammation, and secretion of stress hormones. Moreover, overfeeding, inactivity, intravenous injection of antibiotic solutions, dextrose, and dialysis solutions can induce IR [3].

The patient infected with COVID-19 experiences psychological stress, depression, and anxiety. Some uninfected subjects also have high levels of stress due to work or virus infection. Under stress, the immune system cannot respond to hormonal changes, and consequently, inflammation can increase the risk of metabolic disease. Stress-induced inflammation is a main contributing factor to induce IR. Stress in COVID-19 patients can stimulate the hypothalamicpituitary-adrenal (HPA) axis. Cortisol, catecholamines, growth hormone, and glucagon are secreted in response to physiological stress. Plasma levels of these stress hormones can increase 2-5 folds during stress, which in a short period can induce IR [7]. Furthermore, the secretion of stress hormones can elevate blood-free fatty acid (FFA) levels. Increased FFA levels can decrease insulin sensitivity and inhibit insulin signaling.

Quarantine and a short bed rest time (e.g., 3-5 days) in healthy subjects can reduce insulin sensitivity. It has been documented that only 5 days of bed rest can induce IR, increase triglyceride, cholesterol, and blood pressure in healthy volunteers. Longer bed rest (about 9-day) is also associated with reduced insulin sensitivity and may develop IR in healthy subjects [3]. Therefore, monitoring programs are necessary in the post-coronavirus world.

In summary, hyperglycemia in COVID-19 patients is related to severe complications and mortality rates. Strict blood glucose control is essential during and after the treatment of COVID-19. Hence, blood glucose level monitoring is a medical necessity during the COVID-19 pandemic to prevent type 2 diabetes. In addition to glycaemic conditions, various factors, such as healthy nutrition, appropriate medicine, and regular exercise, should be considered by COVID-19 patients. 


\section{CONFLICT OF INTEREST}

Dr. Ebrahim Abbasi is the editorial board member of The Open Medicinal Chemistry Journal.

\section{ACKNOWLEDGEMENTS}

Declared none.

\section{REFERENCES}

[1] Kassaee, S.M.; Taghi Goodarzi, M.; Abbasi Oshaghi, E. Antioxidant, antiglycation and anti-hyperlipidemic effects of trigonella foenum and cinnamon in type 2 diabetic rats. Jundishapur J. Nat. Pharm. Prod., 2018, 13 (1).

[2] Abbasi-Oshaghi, E.; Khodadadi, I.; Mirzaei, F.; Ahmadi, M.; Tayebinia, H.; Goodarzi, M.T. Anethum graveolens L. alleviates sperm damage by limiting oxidative stress and insulin resistance in diabetic rats. Open Med. Chem. J., 2020, 14 (1).

[http://dx.doi.org/10.2174/1874104502014010035]

[3] Mirzaei, F; Khodadadi, I; Vafaei, SA; Abbasi-Oshaghi, E; Tayebinia,
H; Farahani, F Importance of hyperglycemia in COVID-19 intensivecare patients: Mechanism and treatment strategy. Prim. Care Diabetes, 2021.

[http://dx.doi.org/10.1016/j.pcd.2021.01.002]

[4] Bornstein, SR; Dalan, R; Hopkins, D; Mingrone, G; Boehm, BO Endocrine and metabolic link to coronavirus infection. Nat. Rev. Endocrinol., 2020.

[http://dx.doi.org/10.1038/s41574-020-0353-9]

[5] Farahani, F.; Mirzaei, F.; Khodadadi, I.; Abbasi-Oshaghi, E. Importance of hyperglycemia in preoperative, intraoperative and postoperative periods in COVID-19 patients. Int. J. Surg., 2020, 83, $1-2$.

[http://dx.doi.org/10.1016/j.ijsu.2020.08.048] [PMID: 32927136]

[6] Koskela, H.O.; Salonen, P.H.; Romppanen, J.; Niskanen, L. Long-term mortality after community-acquired pneumonia-impacts of diabetes and newly discovered hyperglycaemia: A prospective, observational cohort study. BMJ Open, 2014, 4(8), e005715.

[http://dx.doi.org/10.1136/bmjopen-2014-005715] [PMID: 25146717]

[7] Xiu, F; Stanojcic, M Stress hyperglycemia, insulin treatment, and innate immune cells. 2014.

[http://dx.doi.org/10.1155/2014/486403]

C 2021 Tavilani and Abbasi

This is an open access article distributed under the terms of the Creative Commons Attribution 4.0 International Public License (CC-BY 4.0), a copy of which is available at: https://creativecommons.org/licenses/by/4.0/legalcode. This license permits unrestricted use, distribution, and reproduction in any medium, provided the original author and source are credited. 